\title{
THE RELATIONSHIP BETWEEN TAUROCHOLATE SECRETION RATE AND BILE PRODUCTION IN THE UNANESTHETIZED DOG DURING CHOLINERGIC BLOCKADE AND DURING SECRETIN ADMINISTRATION *
}

\author{
By RUDOLF PREISIG, $\dagger$ HERBERT L. COOPER AND HENRY O. WHEELER $\ddagger$
}

(From the Department of Medicine, Columbia University College of Physicians and Surgeons, and The Presbyterian Hospital, New York, N. Y.)

(Submitted for publication December 12, 1961 ; accepted January 15, 1962)

The energy for bile formation must be derived from intrahepatic processes rather than from the hydrostatic pressure of the blood (1). As Sperber has indicated (2), there is a variety of reasons for believing that the secretion of organic anions, and particularly of bile salts, may play a primary role in the production of bile. The bile salts are secreted by active transport (3), they constitute a substantial fraction of the total bile solutes, and are very effective choleretics in most species (4-6). Therefore, one of the objectives of the present studies was the exploration of the relationship between taurocholate secretion and the output of water and inorganic electrolytes in the bile.

Previous studies (7) demonstrated the occurrence of marked spontaneous fluctuations in bile flow and composition in unanesthetized dogs even during constant infusions of sodium taurocholate. These fluctuations were thought to represent the addition of variable quantities of an alkaline fluid similar to that which is produced in abundance during secretin stimulation. These findings suggested the existence of transport mechanisms altogether independent of taurocholate secretion. In order to explore this possibility, a detailed examination of the effects of intravenous secretin was also included in the present work.

The spontaneous fluctuations in bile flow and composition, although significant in themselves, constituted a technical obstacle to the systematic study of the effects of varying rates of taurocholate secretion. It was therefore desirable to minimize these fluctuations. This was accomplished by ad-

* This investigation was supported by grants from the U. S. Public Health Service (Grant A-4011) and the New York Heart Association.

† Robert P. Boylan Research Fellow, New York Heart Association.

$\ddagger$ Markle Scholar in Medical Science. ministration of the cholinergic blocking agent, pipenzolate methylbromide, which was employed because of its reported effectiveness in blocking the response of the human pancreas to secretin (8). Although the mechanism of action of this agent in relation to canine biliary secretion was not clear, it provided a useful empirical means of approaching a reproducible reference state at each of the rates of taurocholate secretion under study.

\section{METHODS}

All studies were conducted on four trained, unanesthetized, adult female mongrel dogs (weights, 20 to $25 \mathrm{~kg}$ ), which had been prepared several months previously by splenectomy, cholecystectomy, and installation of a Thomas duodenal cannula (9). Food and water were withheld for 15 hours prior to each study.

A commercial preparation of "sodium taurocholate," 1 in which bile salts accounted for approximately 75 per cent of the total solids (7), was used for intravenous infusion. A 6 per cent aqueous solution of this material was passed through a Seitz filter and then diluted with 5 per cent dextrose in water to a final concentration of 1.3 per cent, which was approximately isotonic. Taurocholate infusions were administered by means of a Bowman infusion pump through a small nylon catheter which had been introduced into a peripheral vein and advanced to the region of the superior or inferior vena cava.

Secretin ${ }^{2}$ was diluted to $5 \mathrm{U}$ per $\mathrm{ml}$ in normal saline and given intravenously at the rate of $2.5 \mathrm{U}$ per minute for a total period of 20 minutes, except during the exploration of dose-response relationships (see Results, section B). Pipenzolate methylbromide ${ }^{3}$ was diluted to 2.5 $\mathrm{mg}$ per $\mathrm{ml}$ in normal saline and administered intravenously at the rate of $0.1 \mathrm{mg}$ per $\mathrm{kg}$ per 5 minutes for the first 60 minutes, thereafter at the rate of $0.1 \mathrm{mg}$ per $\mathrm{kg}$ per 10 minutes.

All studies were conducted with the animal in the up-

\footnotetext{
1 Purchased from Nutritional Biochemicals Corp.

${ }^{2}$ Secretin was supplied by Eli Lilly \& Co. through the courtesy of Dr. James B. Hammond.

${ }^{3}$ Supplied as "Piptal" by Lakeside Laboratories through the courtesy of Dr. Harry M. Leyland.
} 
right position in a sling, and bile collections were carried out as reported elsewhere in detail (7). In each experiment bile collection was begun at least 60 minutes after the start of the taurocholate infusion in order to achieve equilibration. When the taurocholate infusion rate was changed during the course of a study, at least 45 minutes were allowed for equilibration at the new level. During secretin administration, bile for analysis was collected after 10 minutes had been allowed for the establishment of a constant choleresis. When pipenzolate methylbromide was administered, bile collection was delayed at least 45 minutes, by which time clinical signs of cholinergic blockade were evident.

$\mathrm{pH}$ was measured anaerobically with a Cambridge glass electrode apparatus. Total $\mathrm{CO}_{2}$ content was determined by the method of Van Slyke and Stadie (10), and bicarbonate was calculated from the Henderson-Hasselbalch equation (assuming a $\mathrm{pK}_{\mathrm{a}}$ of 6.1). Sodium and potassium were measured by flame spectrophotometry, chloride by the method of Cotlove, Trantham and Bowman (11), and freezing point depressions in a Fiske osmometer.

"Taurocholate" concentrations in bile were calculated by the formula, $\left[\mathrm{T}^{-}\right]=\left(\left[\mathrm{Na}^{+}\right]+\left[\mathrm{K}^{+}\right]\right)-\left(\left[\mathrm{Cl}^{-}\right]+\right.$ $\left.\left[\mathrm{HCO}_{3}^{-}\right]\right)$, which was found to yield results in good agreement with bile acid concentrations obtained by direct chemical analysis (7). Although dihydroxy as well as trihydroxy bile acids were present in the infused material and in the bile, the term "taurocholate" is used for convenience throughout this report to designate the total concentration of conjugated bile acids.

\section{RESULTS}

A. Relationship between bile production and taurocholate excretion rate. The rates of infusion of sodium taurocholate employed in the present studies did not exceed the usual biliary taurocholate "transport maximum" (about 110 to $140 \mu$ moles per minute) for animals of this size (3). Hence, as expected from earlier studies (7), the biliary excretion rate of taurocholate always achieved and maintained a value approximately equal to the rate of administration of this bile salt. Taurocholate excretion rate could thus be "set" at a variety of different levels by selection of the appropriate infusion rates.

When the separate studies on each of the four dogs during cholinergic blockade (open circles) were plotted as shown in Figure 1, an approximately linear relationship was observed between bile flow and taurocholate excretion rate, and a straight line was fitted by eye. The number of milliliters of bile formed per micromole of taurocholate excreted, estimated from the slope of this
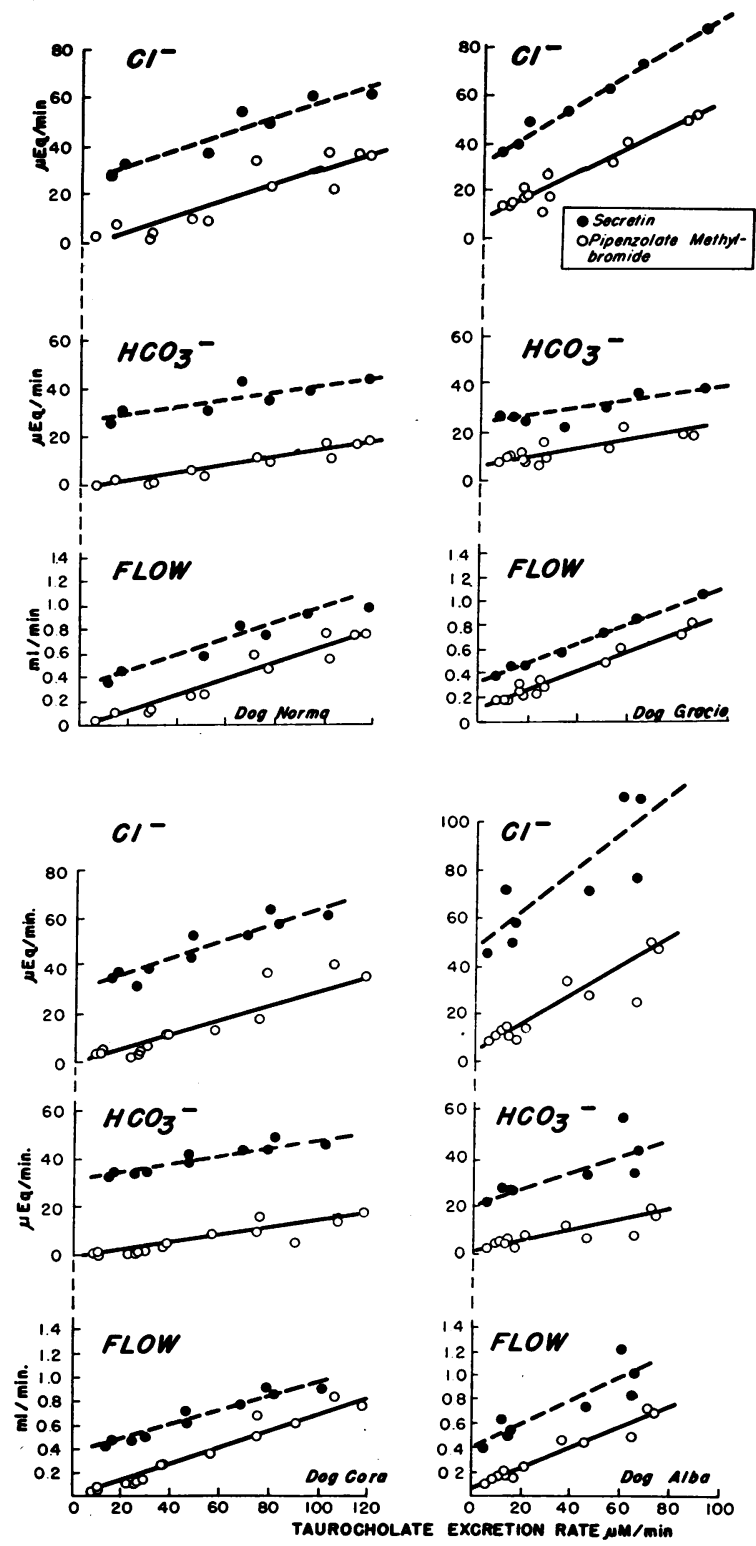

Fig. 1. Bile flow, Chloride, and bicarbonate exCRETION AS FUNCTIONS OF TAUROCHOLATE EXCRETION RATE DURING CHOLINERGIC BLOCKADE (OPEN CIRCLES) AND DURING SECRETIN ADMINISTRATION (CLOSED CIRCLES).

line, was $0.007,0.007,0.008$, and 0.009 in the four dogs. ${ }^{4}$

Like the output of water, the biliary excretion of chloride and bicarbonate ions was also dependent upon the rate of taurocholate excretion, and

4 Throughout the text, tables, and figures, the data relating to individual dogs will always be presented in the same order: Norma, Cora, Gracie, Alba. 
straight lines were drawn to fit these data in each $\operatorname{dog}$ (Figure 1). From the slopes of these lines it was possible to calculate the approximate number of microequivalents of these ions excreted per micromole of taurocholate excreted. In the case of chloride these values were $0.33,0.31,0.50$, and 0.60 , and in the case of bicarbonate, $0.15,0.15$, 0.16 , and 0.22 .

Variations in the concentration of chloride and bicarbonate were observed (Figure 2). The only consistent feature in all four dogs was the comparatively high chloride concentration noted at the very lowest rates of taurocholate excretion. The fundamental dependence of the excretion of chloride and bicarbonate upon taurocholate excretion is shown in Figure 1. However, it is evident that the linearity of these relationships is not established. The calculation of chloride: taurocholate and bicarbonate: taurocholate ratios is therefore regarded for the present as an arbitrary approximation intended only to provide a rough indication
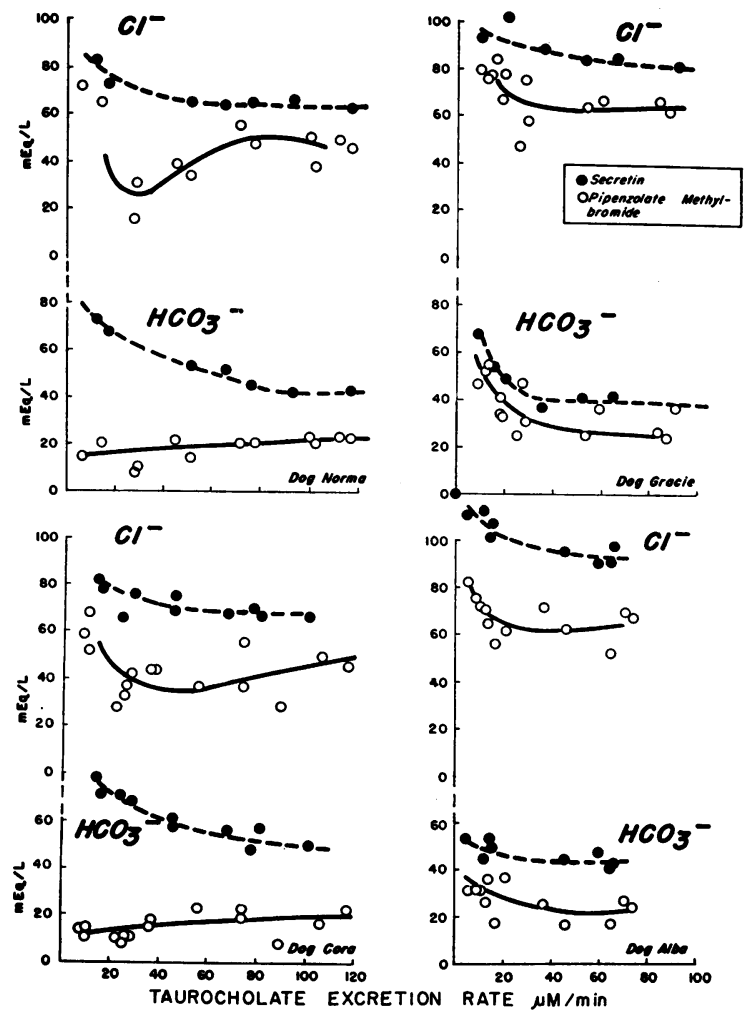

Fig. 2. Concentration of Chloride and BicarboNATE IN BILE DURING THE EXPERIMENTS PLOTTED IN FIGURE 1.

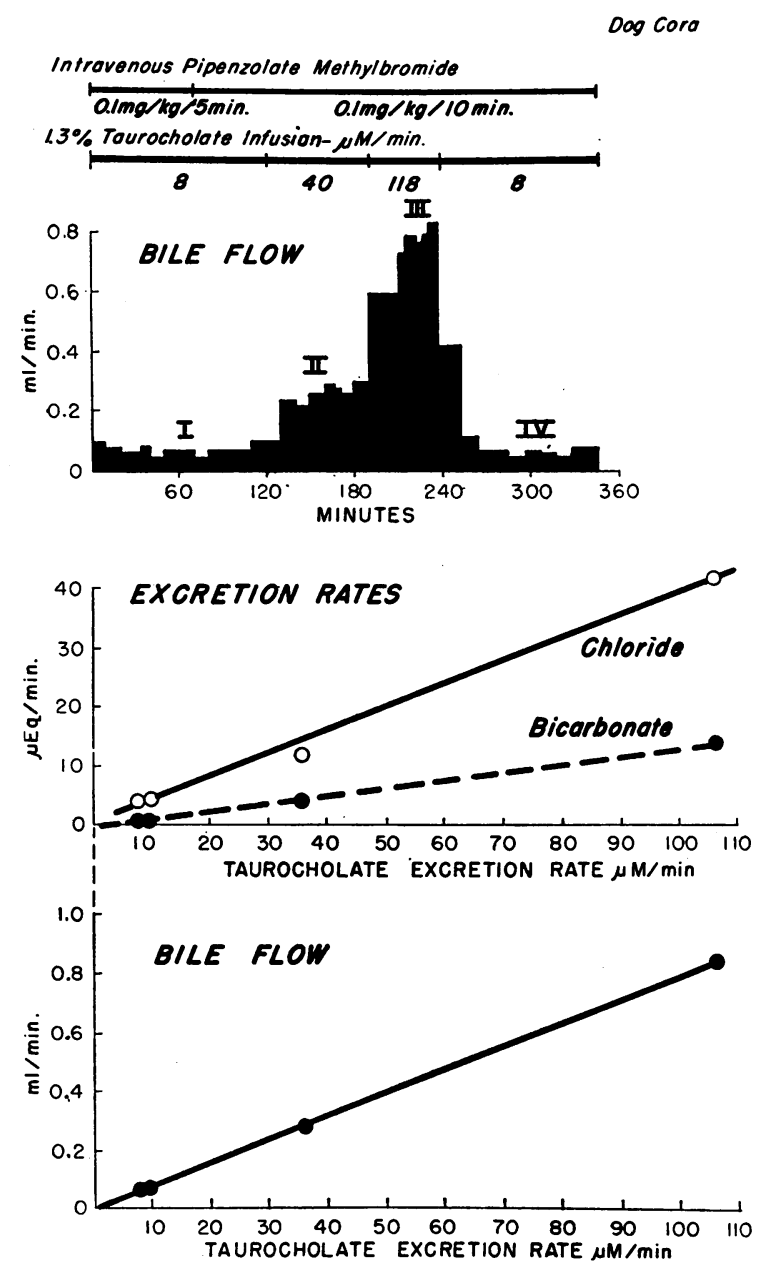

Fig. 3. EfFect of varying taurocholate excretion RATE, DURING THE COURSE OF A SINGLE STUDY, ON BILE FLOW AND ON THE EXCRETION RATES OF CHLORIDE (OPEN CIRCLES) AND BICARBONATE (CLOSED CIRCLES) DURING CHOLINERGIC BLOCKADE.

of the number of chloride and bicarbonate ions obligated by each taurocholate ion excreted.

In a single study on each dog in which taurocholate was infused at different rates within the same day (thereby eliminating day-to-day variations) all of the above results were confirmed. These data are presented in Table I and a typical study is illustrated in Figure 3.

$B$. Effect of intravenous secretin. When secretin was administered intravenously at 1-minute intervals during the course of a continuous taurocholate infusion, bile flow increased and achieved a constant level within 10 minutes. This constant flow was maintained by continuing secretin injec- 
TAUROCHOLATE SECRETION AND BILE PRODUCTION

TABLE I

Effect of varying taurocholate excretion rates within a single study

\begin{tabular}{|c|c|c|c|c|c|c|c|c|c|c|c|}
\hline Dog & $\begin{array}{c}\text { Approx. } \\
\text { tauro- } \\
\text { cholate } \\
\text { infusion* }\end{array}$ & $\begin{array}{l}\text { Tauro- } \\
\text { cholate } \\
\text { excr. }\end{array}$ & $\begin{array}{l}\text { Bile } \\
\text { flow }\end{array}$ & $\begin{array}{l}\text { Tauro- } \\
\text { cholate } \\
\text { conc. }\end{array}$ & $\begin{array}{l}\mathrm{Na}^{+} \\
\text {conc. }\end{array}$ & $\begin{array}{c}\mathrm{K}^{+} \\
\text {conc. }\end{array}$ & $\begin{array}{l}\mathrm{Cl}^{-} \\
\text {conc. }\end{array}$ & $\begin{array}{c}\mathrm{HCO}_{2}^{-} \\
\text {conc. }\end{array}$ & $\begin{array}{c}\mathrm{Cl}^{-} \\
\text {excr. }\end{array}$ & $\underset{\text { excr. }}{\mathrm{HCO}_{3}^{-}}$ & $\begin{array}{l}\text { Bile } \\
\text { pH }\end{array}$ \\
\hline & \multicolumn{2}{|c|}{ $\mu$ moles $/ \mathrm{min}$} & $m l / \min$ & mmoles $/ L$ & \multicolumn{2}{|c|}{$m E q / L$} & \multicolumn{2}{|c|}{$m E q / L$} & \multicolumn{2}{|c|}{$\mu E q / \min$} & \\
\hline Norma & $\begin{array}{r}118 \\
40 \\
8 \\
118\end{array}$ & $\begin{array}{r}102 \\
45 \\
14 \\
100\end{array}$ & $\begin{array}{l}0.58 \\
0.26 \\
0.12 \\
0.77\end{array}$ & $\begin{array}{l}176 \\
173 \\
121 \\
130\end{array}$ & $\begin{array}{l}224 \\
226 \\
200 \\
196\end{array}$ & $\begin{array}{l}8.3 \\
8.3 \\
6.5 \\
6.9\end{array}$ & $\begin{array}{l}38 \\
39 \\
65 \\
50\end{array}$ & $\begin{array}{l}19 \\
21 \\
20 \\
23\end{array}$ & $\begin{array}{r}22 \\
10 \\
8 \\
38\end{array}$ & $\begin{array}{r}11 \\
6 \\
3 \\
17\end{array}$ & $\begin{array}{l}7.28 \\
7.38 \\
7.31 \\
7.40\end{array}$ \\
\hline Cora & $\begin{array}{r}8 \\
40 \\
118 \\
8\end{array}$ & $\begin{array}{r}8 \\
36 \\
106 \\
10\end{array}$ & $\begin{array}{l}0.07 \\
0.28 \\
0.84 \\
0.07\end{array}$ & $\begin{array}{l}127 \\
128 \\
126 \\
143\end{array}$ & $\begin{array}{l}193 \\
180 \\
186 \\
199\end{array}$ & $\begin{array}{l}7.4 \\
7.0 \\
6.4 \\
6.8\end{array}$ & $\begin{array}{l}59 \\
44 \\
50 \\
52\end{array}$ & $\begin{array}{l}14 \\
15 \\
17 \\
11\end{array}$ & $\begin{array}{r}4 \\
12 \\
42 \\
4\end{array}$ & $\begin{array}{r}1 \\
4 \\
14 \\
1\end{array}$ & $\begin{array}{l}6.82 \\
7.15 \\
7.31 \\
6.70\end{array}$ \\
\hline Gracie & $\begin{array}{r}8 \\
29 \\
69 \\
8\end{array}$ & $\begin{array}{l}13 \\
27 \\
59 \\
12\end{array}$ & $\begin{array}{l}0.19 \\
0.35 \\
0.60 \\
0.19\end{array}$ & $\begin{array}{l}66 \\
77 \\
98 \\
63\end{array}$ & $\begin{array}{l}194 \\
193 \\
197 \\
186\end{array}$ & $\begin{array}{l}4.5 \\
4.8 \\
5.3 \\
4.7\end{array}$ & $\begin{array}{l}77 \\
75 \\
67 \\
76\end{array}$ & $\begin{array}{l}55 \\
47 \\
37 \\
52\end{array}$ & $\begin{array}{l}15 \\
26 \\
40 \\
14\end{array}$ & $\begin{array}{l}10 \\
16 \\
22 \\
10\end{array}$ & $\begin{array}{l}7.72 \\
7.63 \\
7.63 \\
7.70\end{array}$ \\
\hline Alba & $\begin{array}{r}8 \\
40 \\
80 \\
8\end{array}$ & $\begin{array}{r}11 \\
37 \\
71 \\
9\end{array}$ & $\begin{array}{l}0.18 \\
0.46 \\
0.73 \\
0.15\end{array}$ & $\begin{array}{l}63 \\
81 \\
97 \\
61\end{array}$ & $\begin{array}{l}161 \\
171 \\
185 \\
160\end{array}$ & $\begin{array}{l}5.3 \\
6.3 \\
6.5 \\
6.1\end{array}$ & $\begin{array}{l}72 \\
71 \\
69 \\
75\end{array}$ & $\begin{array}{l}31 \\
25 \\
26 \\
31\end{array}$ & $\begin{array}{l}13 \\
33 \\
50 \\
11\end{array}$ & $\begin{array}{r}6 \\
12 \\
19 \\
5\end{array}$ & $\begin{array}{l}7.46 \\
7.44 \\
7.45 \\
7.52\end{array}$ \\
\hline
\end{tabular}

* Constant taurocholate infusions were administered in the order indicated. At least 1 hour was allowed for equilibration before collection of bile specimens. Pipenzolate methylbromide was administered at the rate of $0.1 \mathrm{mg} / \mathrm{kg} / 5$ minutes for the first 60 minutes, and thereafter at the rate of $0.1 \mathrm{mg} / \mathrm{kg} / 10$ minutes.

TABLE II

Secretin-induced excretion of biliary water, chloride, and bicarbonate, compared with excretion of these constituents during cholinergic blockade

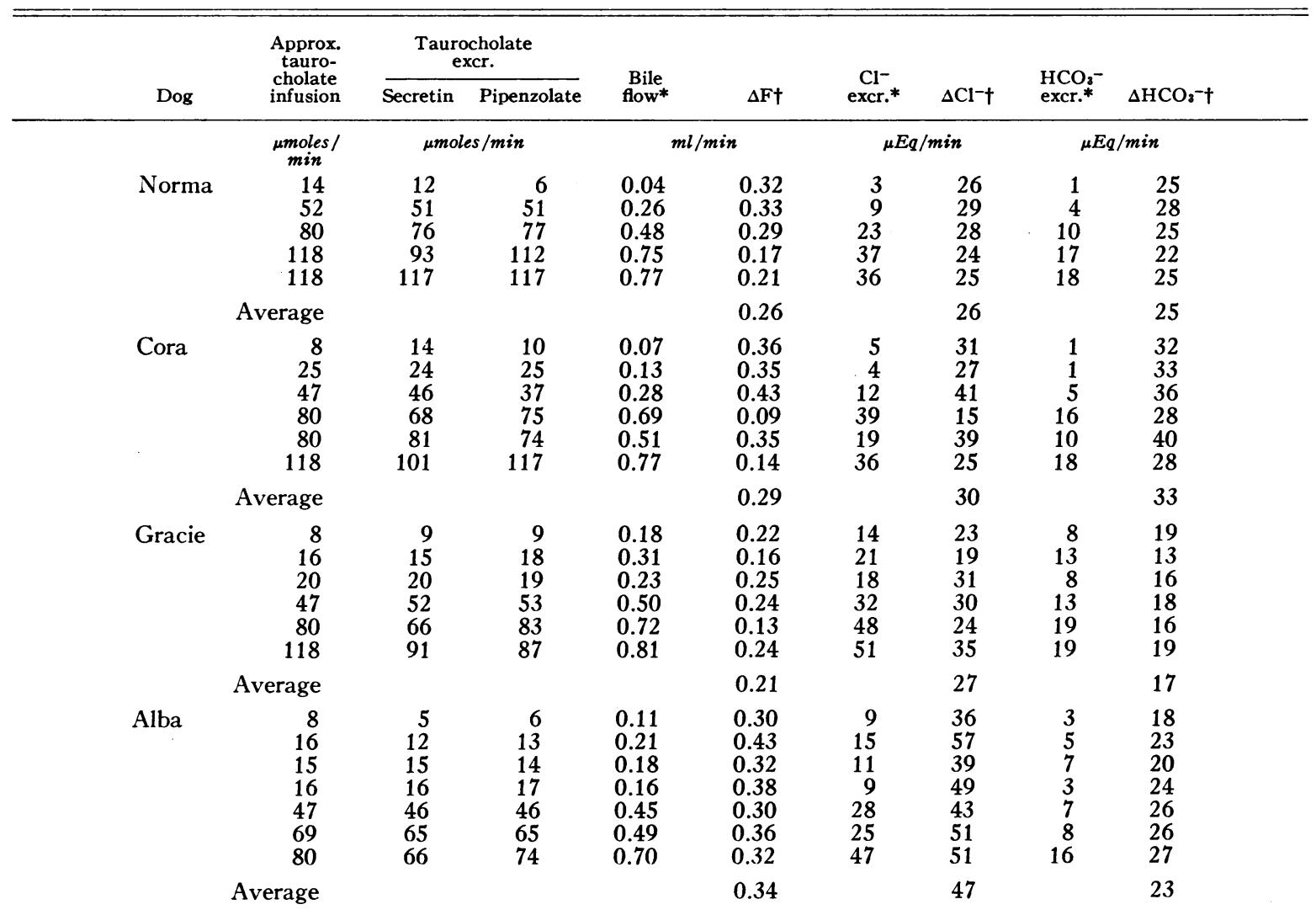

* Bile flow, chloride, and bicarbonate excretion rates during cholinergic blockade with pipenzolate methylbromide. $\dagger$ Secretin-induced increments, calculated by subtracting bile flow, chloride output, and bicarbonate output during cholinergic blockade from the values observed during secretin administration. 
tions, and a representative bile specimen was collected during the succeeding 10 minutes. Doses of secretin ranging from 0.625 to $5 \mathrm{U}$ per minute were administered in this manner to each of three dogs and it appeared that the minimal dose capable of eliciting a maximal choleresis was approximately $2.5 \mathrm{U}$ per minute. Therefore, this dose was used throughout all subsequent studies.

Five to seven studies were conducted on each $\operatorname{dog}$ at taurocholate infusion rates ranging from 8 to $118 \mu$ moles per minute (Table II). Bile flow and composition were measured during secretin stimulation and-allowing time for the secretin effect to disappear-subsequently during the administration of the cholinergic blocking agent, pipenzolate methylbromide. The bile flow during secretin administration exceeded the flow during cholinergic blockade by a relatively constant amount (average, 0.26, 0.29, 0.21, and $0.34 \mathrm{ml}$ per minute in the four dogs), regardless of the excretion rate of taurocholate. Similarly, consistent increments in the excretion rates of chloride (26, 30,27 , and $47 \mu \mathrm{Eq}$ per minute) and bicarbonate $(25,33,17$, and $23 \mu \mathrm{Eq}$ per minute) were elicited by secretin administration at all rates of taurocholate excretion. As expected, the excretion rate of taurocholate itself was approximately equal to the rate of infusion and was unaltered by either secretin or pipenzolate methylbromide administration.
The effect of secretin is illustrated graphically in Figure 1 (closed circles), in which all of the observations during secretin administration have been plotted. It is evident that nearly constant increments in chloride, bicarbonate, and water output are elicited by this hormone at all levels of taurocholate excretion. In keeping with these observations, the concentrations of chloride and bicarbonate (Figure 2) were increased during secretin stimulation.

In relation to effects of secretin stimulation, the possibility of contamination of bile specimens with pancreatic juice was considered. Since the sampling catheter was always advanced about $7 \mathrm{~cm}$ into the common bile duct, the possibility of reflux of fluid from the orifice of the minor pancreatic duct seems remote. Moreover, no amylase was detected in bile specimens obtained from these dogs during secretin administration, using a semiquantitative test of sufficient sensitivity to detect the amylase in high dilutions of duodenal juice (7). Similar responses to secretin have been observed in a dog whose minor pancreatic duct was ligated and divided.

C. Experimental reference state. As stated in the introduction, a means was sought to minimize the variations in bile flow and composition which normally occur in the unanesthetized dog even during constant rates of taurocholate excretion. It had appeared that these variations might be

TABLE III

Variations in bile flow observed at 5-minute intervals during continuous intravenous taurocholate infusion* with and without cholinergic blockade

\begin{tabular}{|c|c|c|c|c|c|c|c|c|}
\hline & \multicolumn{8}{|c|}{ Bile flow } \\
\hline & \multicolumn{2}{|c|}{ Norma } & \multicolumn{2}{|c|}{ Cora } & \multicolumn{2}{|c|}{ Gracie } & \multicolumn{2}{|c|}{ Alba } \\
\hline & Control & Pip. meth. $\dagger$ & Control & Pip. meth. & Control & Pip. meth. & Control & Pip. meth. \\
\hline & \multicolumn{2}{|c|}{$\mathrm{ml} / \mathrm{min}$} & \multicolumn{2}{|c|}{$m l / m i n$} & \multicolumn{2}{|c|}{$\mathrm{ml} / \mathrm{min}$} & \multicolumn{2}{|c|}{$m l / m i n$} \\
\hline & $\begin{array}{l}0.11 \\
0.08 \\
0.14 \\
0.16 \\
0.17 \\
0.18 \\
0.13 \\
0.18 \\
0.18\end{array}$ & $\begin{array}{l}0.10 \\
0.07 \\
0.10 \\
0.08 \\
0.09 \\
0.10 \\
0.08 \\
0.10 \\
0.09\end{array}$ & $\begin{array}{l}0.22 \\
0.30 \\
0.13 \\
0.17 \\
0.20 \\
0.32 \\
0.32 \\
0.28 \\
0.17\end{array}$ & $\begin{array}{l}0.14 \\
0.14 \\
0.14 \\
0.16 \\
0.14 \\
0.14 \\
0.14 \\
0.14 \\
0.14\end{array}$ & $\begin{array}{l}0.21 \\
0.22 \\
0.22 \\
0.20 \\
0.24 \\
0.32 \\
0.32 \\
0.34 \\
0.32\end{array}$ & $\begin{array}{l}0.20 \\
0.22 \\
0.28 \\
0.26 \\
0.26 \\
0.26 \\
0.24 \\
0.26 \\
0.24\end{array}$ & $\begin{array}{l}0.34 \\
0.30 \\
0.26 \\
0.22 \\
0.20 \\
0.22 \\
0.20 \\
0.22 \\
0.19\end{array}$ & $\begin{array}{l}0.18 \\
0.22 \\
0.22 \\
0.21 \\
0.23 \\
0.24 \\
0.24 \\
0.24 \\
0.24\end{array}$ \\
\hline $\begin{array}{l}\text { Mean } \\
\text { SD }\end{array}$ & $\begin{array}{l}0.15 \\
0.033\end{array}$ & $\begin{array}{l}0.09 \\
0.010\end{array}$ & $\begin{array}{l}0.23 \\
0.085\end{array}$ & $\begin{array}{l}0.14 \\
0.007\end{array}$ & $\begin{array}{l}0.27 \\
0.054\end{array}$ & $\begin{array}{l}0.25 \\
0.036\end{array}$ & $\begin{array}{l}0.24 \\
0.048\end{array}$ & $\begin{array}{l}0.22 \\
0.019\end{array}$ \\
\hline
\end{tabular}

* Rate of taurocholate administration, approximately $24 \mu$ moles $/$ minute.
$\dagger$ Pip. meth. = pipenzolate methylbromide. Rate of administration: $0.1 \mathrm{mg} / \mathrm{kg} / 5$ minutes i.v. for first 60 minutes; $0,1 \mathrm{mg} / \mathrm{kg} / 10$ minutes thereafter. 


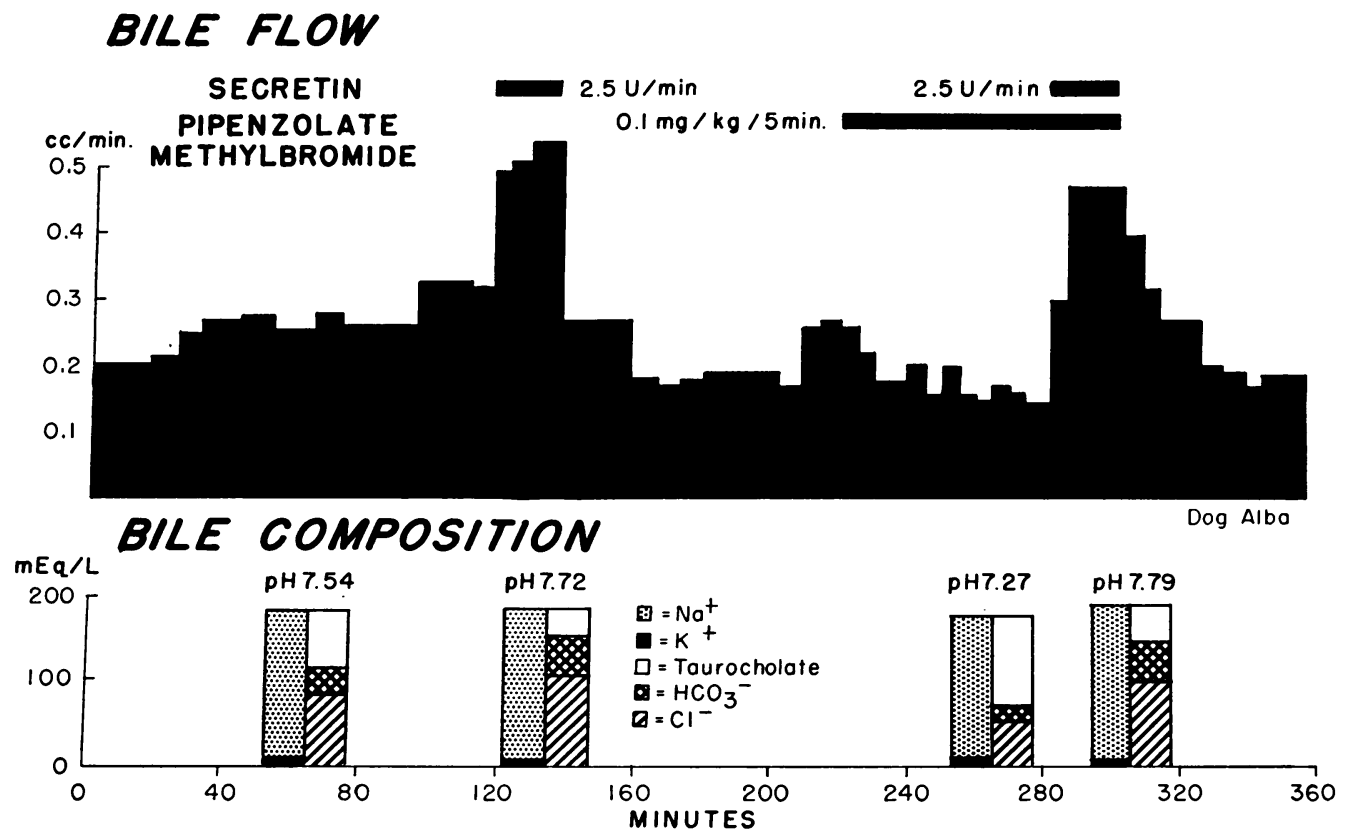

Fig. 4. IDENTICAL EFFECTS OF SECRETIN ADMINISTRATION ON FLOW AND COMPOSITION OF BILE With and without administration of pipenzolate methylbromide. Sodium taurocholate was infused at a rate of $18 \mu$ moles per minute throughout the study.

attributable, at least in part, to the effects of endogenous secretin ( 7$)$. The autonomic blocking agent, pipenzolate methylbromide, was therefore employed because it was reported to depress the response of the human pancreas to secretin (8). Despite the fact that this rationale proved to be fallacious in reference to the canine biliary tract (see below), it was found that variations in bile flow during intravenous administration of the drug were substantially reduced and that bile flow tended to approach and remain at a level comparable to the lowest spontaneous flow observed in the same animal at the same taurocholate infusion rate. This is apparent in Table III, in which typical rates of bile flow over the course of 45 minutes of observation are compared in each of the dogs with and without pipenzolate methylbromide administration. It can be seen that the agent was most effective in decreasing the fluctuations in bile flow in dogs Norma and Cora and least effective in Gracie. The closes of pipenzolate methylbromicle $(0.1 \mathrm{mg}$ per $\mathrm{kg}$ per 5 minutes for 1 hour, and $0.1 \mathrm{mg}$ per $\mathrm{kg}$ per 10 minutes thereafter) employed in these studies produced tachycardia, marked xerostomia, and maximal mydriasis, but there was no alteration in mean arterial pressure (damped mercury manometer, femoral artery) on the six occasions on which it was measured, and the animals remained alert and cooperative.

The mechanism of action of cholinergic blockade in the establishment of a reference state remains unexplained. As shown in Figure 4 (which illustrates one of two virtually identical experiments), the choleretic response to exogenous secretin was not altered by pipenzolate methylbromide. Moreover, in two other experiments it was evident that this agent did not block the release of endogenous secretin, since the usual choleretic response (7) was elicited by intraduodenal infusion of $0.05 \mathrm{~N}$ hydrochloric acid at $7 \mathrm{ml}$ per minute.

Although this type of cholinergic blockade evidently does not inhibit the release or biliary action of endogenous secretin once hydrochloric acid has entered the duodenum. its effect could still be attributable in part to depression of gastric hydrochloric acid production (12). Studlies were therefore undertaken to evaluate the relationship between gastric acid outflow and spontaneous variations in bile flow. In two of the dogs (Norma and Cora), a definite choleresis appeared to follow the spontaneous entry of hydrochloric acid into 
the duodenum (measured by means of a glass electrode located in the duodenum just distal to the pylorus). One of these studies is illustrated in Figure 5. In the other two dogs there were marked variations in duodenal $\mathrm{pH}$ and bile flow but the time relationship was not so obvious. Similar studies were carried out during pipenzolate methylbromide administration, and as already noted (Table III), there was a substantial reduction of the variation in bile flow. During all but one of these studies the duodenal $\mathrm{pH}$ promptly achieved values of 6.5 or above and remained in this range thereafter. However, in one dog (Norma), whose initial duodenal $\mathrm{pH}$ was 1.7 , neutrality was not achieved until 3 hours after the drug was started, although bile flow was stabilized as in other studies. It must be emphasized that the exact location of the $\mathrm{pH}$ electrode in relation to the pylorus is uncertain, and that this technique provides no clue to the actual quantity of acid mov-
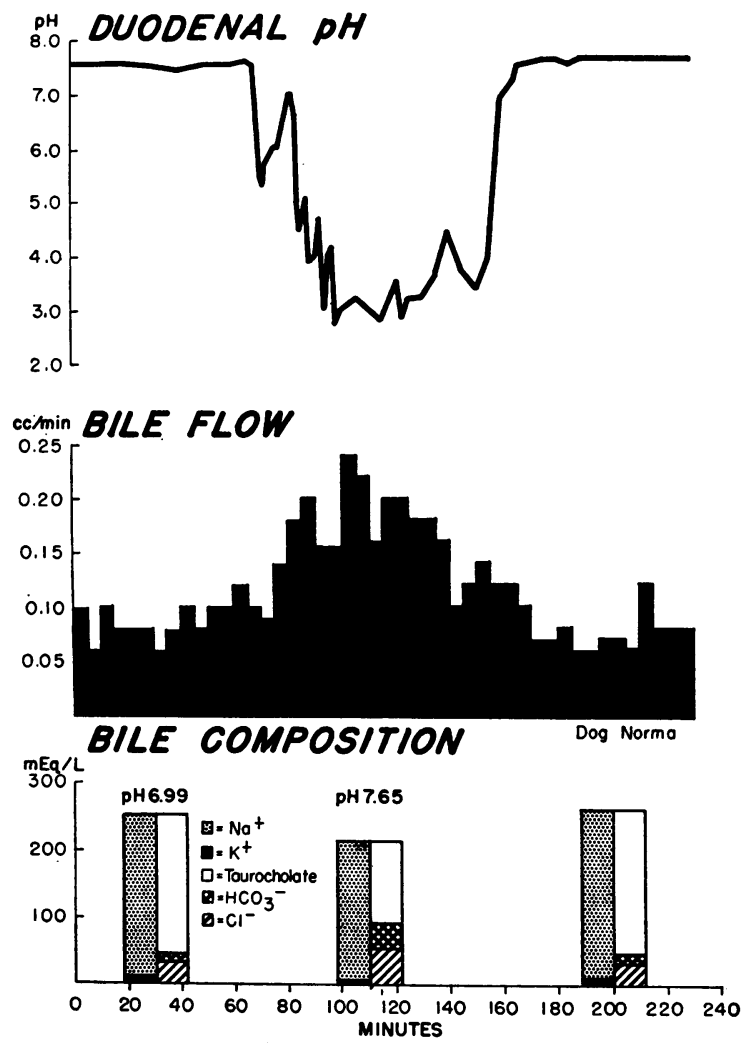

Fig. 5. Spontaneous variations in DUOdenal pH in RELATION TO CHANGES IN BILE FLOW AND COMPOSITION IN DOG Norma. Sodium taurocholate was infused at a constant rate of $18 \mu$ moles per minute. ing into the small intestine, nor to the manner in which it is propelled beyond the point of measurement.

D. Osmolality. Osmolality was determined by freezing point depression on random bile specimens obtained from the four dogs. A total of $17 \mathrm{spec}-$ imens was obtained during secretin choleresis, and 44 specimens during cholinergic blockade. Corresponding plasma samples were collected on 24 occasions (mean plasma osmolality, as recorded in Figure 6, $292 \mathrm{mOsm}$ per $\mathrm{kg}$ ). In spite of the considerable scatter, it is evident from Figure 6 that bile tends to be slightly hypertonic during secretin administration and hypotonic during cholinergic blockade. This impression is underlined by those studies in which simultaneous collection of bile and plasma permitted calculation of bile: plasma osmolality ratios. The mean ratio during secretin administration was 1.10 (range, 1.08 to 1.10 in 7 determinations), whereas the mean ratio was 0.93 (range, 0.77 to 1.03 in 17 determinations) in dogs receiving pipenzolate methylbromide. Although the few observations do not warrant statistical analysis, it would appear from Figure 6 that the difference in osmolality between the two states is most pronounced at higher rates of taurocholate infusion. Thus, it is understandable that the relatively minor osmotic differences between bile and plasma have escaped detection heretofore.

\section{DISCUSSION}

A. Role of active bile salt secretion in bile production. The results of these studies, carried out on the fasting dog under cholinergic blockade, appear to justify the impression that secretion of bile salt anions not only plays a major role, but may be the most important single event in the initiation of bile formation. The output of water and the major inorganic ions was approximately proportional to the output of taurocholate as the latter was varied over a wide range. Extrapolation of this relationship (Figures 1 and 3 ) suggested that bile flows very close to zero could be anticipated in the absence of taurocholate excretion. The single exception was the data obtained in dog Gracie, in which extrapolation suggested a bile flow of approximately $0.1 \mathrm{ml}$ per minute at "zero" taurocholate excretion (see section D). 


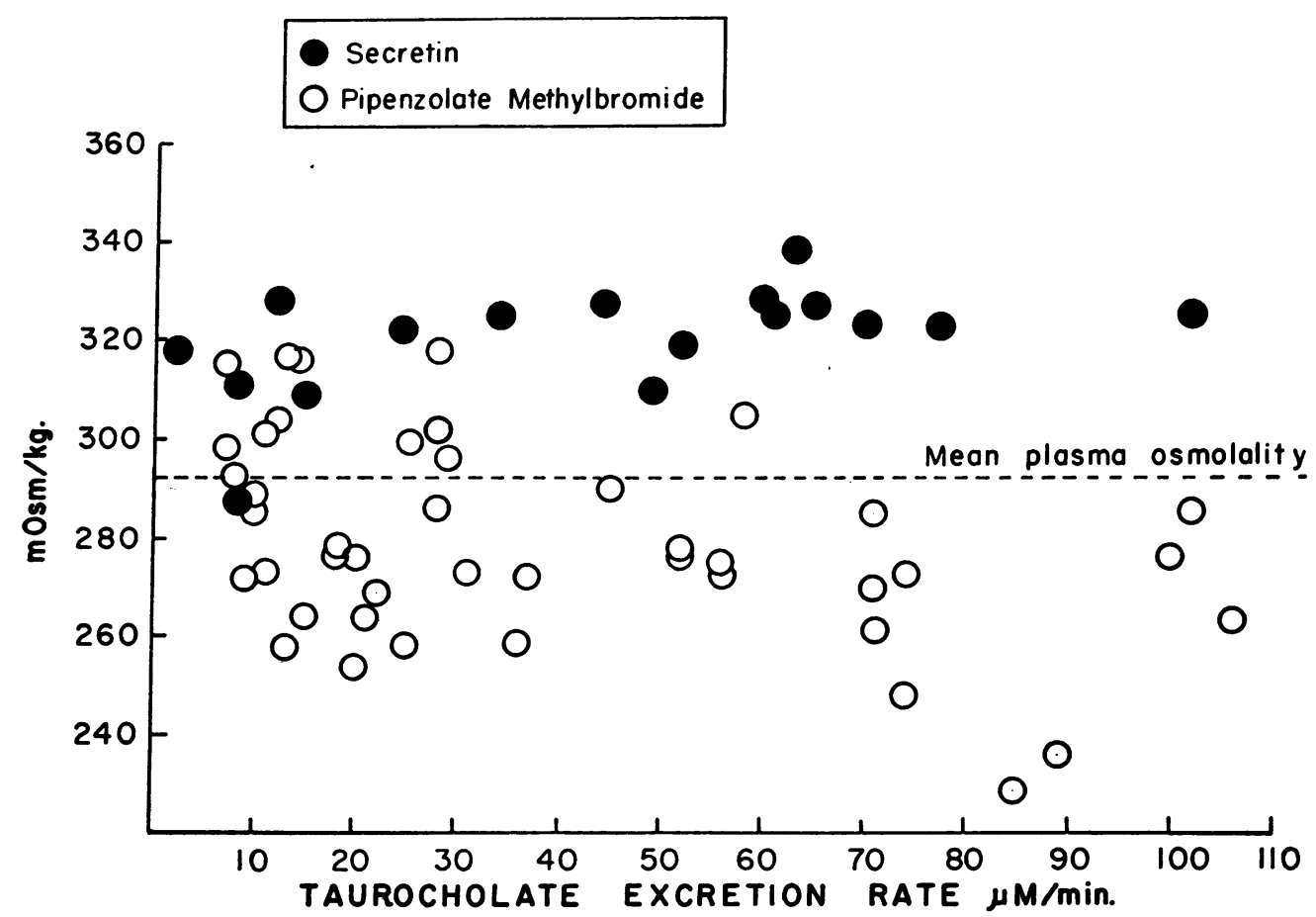

Fig. 6. Osmolality of BILE OBTAINEd DURING CHOLINERgic BLOCKADE (OPEN CIRCLES) AND DURING SECRETIN ADMINISTRATION (CLOSED CIRCLES) AT DIFFERENT RATES OF TAUROCHOLATE EXCRETION. Plasma osmolality (dotted line) is the mean of 24 determinations during these studies.

Reliance on extrapolation is necessary because an actual state of "zero" taurocholate excretion is difficult to realize experimentally, owing to hepatic synthesis of bile salts, and because of the technical problem of collecting the viscous bile produced at low rates of flow (7).

The present finding of increments in the output of water, chloride, and bicarbonate occurring in response to increments in taurocholate output is consistent with the view enunciated by Sperber (2) that the major driving force for bile production is provided by active transport of organic anions (principally bile salts) into the lumen of the biliary tract. It is, of course, not possible to state the actual conditions under which other constituents enter the lumen without measurement of electrical potential and concentration gradients in the appropriate regions of the biliary tract, but the introduction of a relatively nondiffusible anion necessarily creates gradients favorable for entry of water and diffusible solutes.

It could be argued, of course, that the entry of water and the various inorganic electrolytes involves a number of separate active processes, and that a high concentration of taurocholate in the bile simply facilitates these processes or creates a situation unfavorable for reabsorption (just as osmotic diuretic agents interfere with reabsorption of urinary constituents). The experiments reported here do not rule out this possibility. Indeed, in one of the dogs (Gracie; Figure 2 and Table I) bicarbonate concentration in bile regularly exceeded levels normally found in plasma, suggesting that excessive quantities of this ion might have entered the bile by an active transport or exchange mechanism. This does not, however, alter the fact that bile salt secretion, under the present circumstances, is virtually a sine qua non for water and electrolyte excretion, and that the rate of taurocholate secretion is the principal determinant of the final quantity of water and the major electrolytes in the bile.

Since water transport per se does not appear to occur in biological systems (13), and since the present studies suggest that active bile salt secretion can provide the driving force necessary for passive movement of water into the lumen of the biliary tract, one does not have to postulate inde- 
pendent water secretion. This statement is not contradicted by the finding that the osmolality of a number of bile specimens was somewhat lower than that of plasma (Results, section D). These observations apply only to bile as it emerges from the common duct, and the observed hypotonicity may have resulted from active solute reabsorption or perhaps from a change in the state of aggregation of taurocholate ions.

Taurocholate ions have strong associative properties and tend to form micelles at the levels of concentration encountered in bile $(14,15)$. Thus, their osmotic activity is reduced, and the osmotic effectiveness of the bile salt as a whole is mainly attributable to the fact that the anionic micelles are accompanied by an equivalent concentration of cations. Consistent with this phenomenon is the observation that the sum of sodium, potassium, chloride, and bicarbonate concentrations is sufficient to account for the total osmotic activity in bile $(7,16)$. Various bile salts may differ in their associative properties, and variations in choleretic potency may depend to some extent on these differences. In this connection Sperber (2) has suggested that the great choleretic potency of the synthetic "bile acid," dehydrocholate, may be attributable to its lack of associative properties in contrast to the natural conjugated bile acids. The same may be true of a number of synthetic organic acids (17), some of which may have clinical application as choleretics (18).

B. Modifications of bile composition independent of bile salt secretion. If the observations during cholinergic blockade are taken as "baseline" values for bile production at various rates of taurocholate excretion, it is apparent that the administration of secretin at a standard rate results in the additional output of a relatively constant quantity of inorganic electrolytes and water over the entire range of taurocholate excretion. The anatomical site at which this additional fluid enters the bile is unknown. Of interest in this connection is the description by Rous and McMaster (19) of the production of a clear alkaline solution by isolated canine bile ducts, which provides an indication of the inherent secretory capacity of the bile duct epithelium. However, the present evidence does not necessarily permit one to ascribe the effects of secretin to mechanisms located in the duct system, and further studies will be required to establish the site of action of this hormone.

The high bicarbonate content of the additional fluid excreted during secretin adininistration suggests a similarity to pancreatic juice, and may indicate that similar mechanisms are involved in the production of these two fluids. During maximal secretin stimulation the concentration of bicarbonate in bile, like that in pancreatic juice, is so much higher than the plasma bicarbonate concentration that one must suspect the existence of active bicarbonate secretion. A sequence consisting of bicarbonate elaboration followed by bicarbonatechloride exchange has been suggested by Dreiling and Janowitz (20) in connection with the production of pancreatic juice. If analogous phenomena occurred in the biliary tract, this might provide an explanation for the fact that chloride as well as bicarbonate excretion rate increases during secretin administration.

In a number of instances the additional water excreted in response to secretin was less than the amount required to form an isotonic solution with the additional solutes. The average anion concentration in the hypothetical "solution" produced during secretin stimulation, calculated as $\left(\Delta \mathrm{Cl}^{-}+\right.$ $\left.\Delta \mathrm{HCO}_{3}{ }^{-}\right) / \Delta \mathrm{F}$, was approximately $200 \mathrm{mEq}$ per $\mathrm{L}$ in each of the dogs (Table II) with an expected osmolality of $400 \mathrm{mOsm}$ per $\mathrm{kg}$. Consistent with these calculations was the demonstration of hypertonicity by freezing point determinations in bile specimens obtained during secretin stimulation (Figure 6), in contrast to the isotonicity or hypotonicity of bile obtained in the absence of secretin. The observed hypertonicity suggests that secretin-induced electrolyte secretion is not followed by complete osmotic equilibration between the bile and the surrounding tissues.

Pipenzolate methylbromide does not appear to alter the effect of secretin on canine bile production. This would suggest that the mechanisms involved in the response of the canine biliary tract to secretin do not depend upon cholinergic innervation, and may differ in this respect from analogous mechanisms in the human pancreas. However, the possibility that cholinergic stimuli may play a role in bile production under either circumstance (21) has not been ruled out.

C. Spontaneous variations in bile flow and composition. The final composition and flow of 
bile must depend upon the combined activity of at least the two major mechanisms under discussion. Moreover, it is almost certain that many other factors, such as changes in hepatic perfusion, plasma composition, and neurogenic stimuli, must exert a modifying influence not apparent in the relatively steady states prevailing throughout the present studies.

The causes of spontaneous variations in bile flow have not actually been clarified by the present studies. The fact that pipenzolate methylbromide administration tends to produce a reduction and stabilization of bile flow is consistent with previous observations in which atropine was employed (22), but it is not clear whether a direct action on cholinergic nerve endings in the biliary tract is involved. It was evident, at least in some of the present studies, that variations in bile flow were related to the movement of gastric hydrochloric acid into the duodenum, presumably through the mediation of endogenous secretin. To the extent that cholinergic blockade reduces gastric hydrochloric acid production, some of the effects of pipenzolate methylbromide might be explained on this basis. However, the relationship between duodenal $\mathrm{pH}$ and bile flow was not consistent in all animals. It is evident that variations in gastric acid secretion are not the only cause, nor even necessarily a very important cause, of variations in bile flow in the intact animal.

D. Individual and species differences. It has been noted earlier in the Discussion (section A) that one of the four dogs, Gracie, was regularly found to have a greater bile flow and higher bicarbonate concentration than the other dogs, and that a hypothetical flow of about $0.1 \mathrm{ml}$ per minute at "zero" taurocholate excretion rate was predicted by extrapolation. These findings suggested a continuous secretion of inorganic electrolytes with a preponderance of bicarbonate of a degree which was seen in the other animals only during secretin stimulation. While it is possible that this dog elaborated endogenous secretin continuously throughout all of the studies, one must also consider the possibility that the transport of inorganic electrolytes into the biliary tract may have been, to some extent, independent of secretin stimulation.

If the differences between individual members of the same species are noteworthy, it is obvious that there are much more striking differences when other species are compared with the dog. It is well known, for example, that rodents produce copious quantities of bile, that the bile is composed mainly of an alkaline solution of inorganic electrolytes (6), and that the choleretic response to taurocholate is far less than that in the dog (5). This might suggest that there is continuous secretion of large quantities of inorganic ions in rodents, similar to the phenomenon exhibited to a minor degree by dog Gracie. The extent to which the present findings in the dog may be extrapolated to other species, including man, will depend upon the results of future studies, but it is possible that impressive species differences may represent quantitative rather than qualitative dissimilarities in the fundamental mechanisms involved in bile production.

\section{SUMMARY}

Bile flow and electrolyte composition were studied in four unanesthetized cholecystectomized dogs equipped with Thomas cannulae.

The output of water and of the major electrolytes was approximately proportional to the excretion rate of taurocholate during cholinergic blockade. Extrapolation of this relationship suggests bile flows close to zero in the absence of taurocholate excretion.

During secretin administration there were consistent increments in bicarbonate, chloride, and water excretion at all rates of taurocholate excretion, when compared with the flow and composition of bile during cholinergic blockade.

The mechanism of action of cholinergic blockade in establishing a reproducible reference state remains unexplained, but it is suggested that depression of gastric hydrochloric acid secretion (and consequently of release of endogenous secretin) may be a factor in some instances.

Bile tends to be slightly hypertonic during secretin administration, and hypotonic during cholinergic blockade.

The data support the view that bile is formed by the combined activity of two major mechanisms: 1) active secretion of bile salts with passive movement of water and inorganic electrolytes into the lumen along the resulting electrochemical gradients ; 2) independent elaboration of inorganic electrolytes and water, as exemplified by the increments in bicarbonate, chloride, and water ex- 
cretion during secretin administration. It is suggested that additional factors such as changes in hepatic perfusion, plasma composition, and neurogenic stimuli may also affect the final flow and composition of bile.

\section{ACKNOWLEDGMENT}

The authors are indebted to Miss Evelyn Audioun and Miss Elizabeth Dwyer for their invaluable technical assistance.

\section{REFERENCES}

1. Brauer, R. W., Leong, S. F., and Holloway, R. J. Mechanics of bile secretion. Effect of perfusion pressure and temperature on bile flow and bile secretion pressure. Amer. J. Physiol. 1954, 177, 103.

2. Sperber, I. Secretion of organic anions in the formation of urine and bile. Pharmacol. Rev. 1959, 11, 109.

3. Wheeler, H. O., Mancusi-Ungaro, P. L., and Whitlock, R. T. Bile salt transport in the dog (abstract). J. clin. Invest. 1960, 39, 1039.

4. Schiff, M. Gallenbildung, abhängig von der Aufsaugung der Gallenstoffe. Pflüg. Arch. ges. Physiol. 1870, 3, 598.

5. Bizard, G., and Vanlerenberghe, J. Cholérèse et cholérétiques. J. Physiol. (Paris) 1956, 48, 207.

6. Sobotka, H. Physiological Chemistry of the Bile. Baltimore, Williams and Wilkins, 1937, pp. 15, 73.

7. Wheeler, H. O., and Ramos, O. L. Determinants of the flow and composition of bile in the unanesthetized dog during constant infusions of sodium taurocholate. J. clin. Invest. 1960, 39, 161.

8. Dreiling, D. A., and Janowitz, H. D. Inhibitory effect of new anticholinergics on the basal and secretin-stimulated pancreatic secretion in patients with and without pancreatic disease: Therapeutic and theoretic implications. Amer. J. dig. Dis. 1960, $5,639$.

9. Thomas, J. E. An improved cannula for gastric and intestinal fistulas. Proc. Soc. exp. Biol. (N. Y.) 1941, 46, 260.

10. Van Slyke, D. D., and Stadie, W. C. The determination of gases of the blood. J. biol. Chem. 1921, $49,1$.
11. Cotlove, E., Trantham, H. V., and Bowman, R. L. An instrument and method for automatic, rapid, accurate, and sensitive titration of chloride in biologic samples. J. Lab. clin. Med. 1958, 51, 461.

12. Texter, E. C., Jr., Barborka, C. J., and Smith, H. W. Experimental and clinical observations on a new anticholinergic agent, JB 3233 (Piptal) (abstract). Clin. Res. Proc. 1955, 3, 22.

13. Edelman, I. S. Transport through biological membranes. Ann. Rev. Physiol. 1961, 23, 37.

14. Pethica, B. A., and Schulman, J. H. Haemolytic and surface activity of sodium taurocholate. $\mathrm{Na}$ ture (Lond.) 1952, 170, 117.

15. Ekwall, P., Fontell, K., and Norman, A. Smallangle scattering of $\mathrm{x}$-rays in aqueous solutions of sodium salts of conjugated and unconjugated bile acids. Acta chem. scand. 1957, 11, 190.

16. Ravdin, I. S., Johnston, C. G., Riegel, C., and Wright, S. L., Jr. Studies of gall-bladder function. VII. The anion-cation content of hepatic and gall-bladder bile. Amer. J. Physiol. 1932, 100, 317.

17. Gunter, M. J., Kim, K. S., Magee, D. F., Ralston, $\mathrm{H}$., and Ivy, A. C. The choleretic potencies of some synthetic compounds. J. Pharmacol. exp. Ther. 1950, 99, 465.

18. Acheson, E. D., McHardy, G., Dessauer, H. C., Ford, C., and Dunn, D. Effect of florantyrone on rate of secretion of heaptic bile and on its chemical and physical properties. Gastroenterology 1959, 37, 735.

19. Rous, P., and McMaster, P. D. Physiological causes for the varied character of stasis bile. J. exp. Med. 1921, 34, 75.

20. Dreiling, D. A., and Janowitz, H. D. The secretion of electrolytes by the human pancreas. The effect of Diamox, ACTH, and disease. Amer. J. dig. Dis. 1959, 4, 137.

21. Tanturi, C. A., and Ivy, A. C. On the existence of secretory nerves in the vagi for and the reflex excitation and inhibition of bile secretion. Amer. J. Physiol. 1938, 121, 270.

22. Leites, S., and Isabolinskaja, R. Veränderungen des Gallenchemismus und der Gallensekretion unter dem Einfluss einiger inkrete und vegetativen Gifte. Naunyn-Schmiedeberg's Arch. exp. Path. Pharmak. 1933, 170, 592. 